\title{
Hurricane Sandy Recovery Science: A Model for Disaster Research
}

\author{
Eric G. Carbone, PhD; Marcienne M. Wright, PhD, LT USPHS
}

$\mathrm{H}$ urricane Sandy, the largest Atlantic hurricane on record, moved up the East Coast of the United States in October 2012, with a storm surge and wave destruction resulting in at least 117 deaths and $\$ 62$ billion in damage in the United States, primarily in New York and New Jersey. ${ }^{1}$ Almost one-third of all fatalities were due to drowning, while other fatalities resulted from blunt trauma, lacerations, and carbon monoxide poisoning. Following Hurricane Sandy, individuals were faced with recovering physically and mentally and with rebuilding their homes, communities, and health systems as they coped with the adverse health effects of the storm.

At the peak of the storm, over 7.5 million people were without power. Thousands were displaced from their homes, and among those displaced were many individuals requiring treatment for chronic medical conditions or assistance due to disability. A significant number of people were exposed to conditions that exacerbated existing mental health disorders, while others experienced traumatic stress likely to contribute to the emergence of new mental health difficulties in the weeks and months following the storm. Recovery workers and disaster first responders were also exposed to flood, mold, chemical, and physical hazards as they worked to restore services and resources to impacted communities.

Socially or economically disadvantaged groups, such as the poor, the aged, the mentally ill, the physically disabled, and members of historically marginalized ethnic minority groups, are especially vulnerable to the adverse effects of severe weather events. This was no different in the case of Hurricane Sandy, where preliminary findings indicated that a disproportionate number of Sandy-related New York City deaths were among the elderly and the poor. ${ }^{2}$ Preexisting mold contamination, a problem for about one-third of the residents of New York City public housing prior to Hurricane Sandy, was worsened significantly after the storm. $^{3}$

Although natural disasters like Hurricane Sandy cannot be prevented, each brings learning opportunities that can help us mitigate the adverse health outcomes of future events. In fact, the need for disaster-related public health research to inform policy, planning, and practice has never been greater. Much of this important research can only be conducted during the response and recovery. Accordingly, disaster science preparedness focuses on ensuring that the resources and mechanisms are in place to carry out scientific activities effectively and responsibly and provides a framework to support well formulated research on peri- and post-event processes and outcomes. This research contributes to the evidence base critical to improving decision-making for preparedness, response, and recovery and building resilient communities that are better able to cope with future disasters.

In November 2012, subject matter experts were rapidly convened at the New York Academy of Medicine in the early stage of the Hurricane Sandy response to identify disaster research priorities. Priority needs for research were identified in this meeting and included such questions as

- What factors contributed to the resilience of communities or individuals in the aftermath of Hurricane Sandy and why? How can resilience be supported and expanded during recovery efforts?

- How were health care system functions and access to these systems impacted during and immediately after Hurricane Sandy?

- What interventions during Hurricane Sandy response and recovery mitigated adverse mental health outcomes of affected individuals or communities, as well as at-risk individuals?

The US Department of Health and Human Services (HHS) secured a portion of recovery funds specifically for Hurricane Sandy research under the Disaster Relief Appropriations Act of 2013. The HHS Office of the Assistant Secretary for Preparedness and Response (ASPR), the US Centers for Disease Control and Prevention (CDC), and the National Institute for Environmental Health Sciences (NIEHS) funded 31 grants for Hurricane Sandy recovery research and training projects, followed by an additional 13 awards to enhance collaboration among 
grantees and their partners. Since the awarding of these grants, totaling $\$ 20$ million, universities and other institutions have conducted studies by use of a wide range of methods to address multiple topics and research questions identified at the November 2012 expert meeting, including community resilience; evacuation and policy decisionmaking; the public health system response; health care access; mold mitigation and related health issues; characterization of morbidity, disability, and mortality among impacted populations (including behavioral health outcomes of first responders); community and responder education and training; and the use of social media in risk communication. These studies can directly inform Hurricane Sandy recovery efforts, as well as response to and recovery from similar disasters in the future. Significantly, the research funded through these grants was conducted without interfering with the provision of vital assistance to the families and communities affected by the storm.

The collection of studies presented in this issue of Disaster Medicine and Public Health Preparedness addresses important and diverse topics, including perceived stress in the general population following Hurricane Sandy, post-traumatic stress disorder in older adults exposed to the storm, the effectiveness of cellular phone use to transmit real-time shelter morbidity surveillance data, and the effect of the storm on the incidence of emergency department visits. These and other studies to be described in future issues of the journal illustrate that timely and practical research can inform recovery in the impacted areas and contribute to a useful knowledge base for future preparedness, response, and recovery efforts. The public health community should work to develop a rapid disaster research agenda and provide support for long-term and supplemental rapid disaster research and evaluation so that results, like those described in the pages ahead, can be rapidly shared and translated into public health practice for similar disasters anywhere in the United States.

\section{About the Authors}

Office of Public Health Preparedness and Response, US Centers for Disease Control and Prevention, Atlanta, Georgia (Dr Carbone); and Office of the Assistant Secretary for Preparedness and Response, US Department of Health and Human Services, Washington DC (Dr Wright).

Correspondence and reprint requests to Eric G. Carbone, PhD, Centers for Disease Control and Prevention, Office of Public Health Preparedness and Response, 1600 Clifton Road NE, Atlanta, GA 30329 (e-mail: ecarbone@cdc.gov).

\section{Disclaimer}

The findings and conclusions in this Editorial are those of the authors and do not necessarily represent the official position of the US Department of Health and Human Services or the Centers for Disease Control and Prevention.

Published online: December 2, 2015.

\section{REFERENCES}

1. Centers for Disease Control and Prevention. Deaths associated with Hurricane Sandy - October-November 2012. MMWR Morb Mortal Wkly Rep. 2013;62(20):393-397.

2. Faber J. Sandy Social Impact Analysis. Superstorm Sandy Research Initiative. New York University Institute for Public Knowledge website. https://ipk. nyu.edu/initiatives/superstorm-sandy-research-initiative. Accessed August 15, 2015.

3. Alliance for a Just Rebuilding, Alliance for a Greater New York, Community Development Project at the Urban Justice Center, Community Voices Heard, Faith in New York, Families United for Racial and Economic Equality, Good Old Lower East Side, Red Hook Initiative, New York Communities for Change. Weathering the Storm: Rebuilding a More Resilient New York City Housing Authority Post-Sandy. http://www.rebuild ajustny.org/wp-content/uploads/2014/03/Weathering_The_Storm.pdf. Published March 12, 2014. Accessed October 26, 2015. 